\title{
Quentin M. Hope, Social Strata and Social Types in the Maxims of La Rochefoucauld
}

\section{Sergio Poli}

\section{OpenEdition}

1 Journals

\section{Edizione digitale}

URL: https://journals.openedition.org/studifrancesi/37667

DOI: 10.4000/studifrancesi.37667

ISSN: 2421-5856

\section{Editore}

Rosenberg \& Sellier

\section{Edizione cartacea}

Data di pubblicazione: 15 décembre 2004

Paginazione: 606

ISSN: 0039-2944

\section{Notizia bibliografica digitale}

Sergio Poli, «Quentin M. Hope, Social Strata and Social Types in the Maxims of La Rochefoucauld», Studi Francesi [Online], 144 (XLVIII | III) | 2004, online dal 30 novembre 2015, consultato il 08 mai 2021. URL: http://journals.openedition.org/studifrancesi/37667; DOI: https://doi.org/10.4000/studifrancesi. 37667

Questo documento è stato generato automaticamente il 8 mai 2021.

\section{(c) $(1) \odot$}

Studi Francesi è distribuita con Licenza Creative Commons Attribuzione - Non commerciale - Non opere derivate 4.0 Internazionale. 


\section{Quentin M. Hope, Social Strata and Social Types in the Maxims of La Rochefoucauld}

\section{Sergio Poli}

\section{NOTIZIA}

QUENTIN M. HOPE, Social Strata and Social Types in the Maxims of La Rochefoucauld, "Papers on French Seventeenth Century Literature", 59, 2003, pp. 497-505.

1 Come il titolo illustra già chiaramente, il contributo passa in rassegna le "categorie" che alludono al sociale nelle Maximes, e che affiancano, ad un livello meno generale, le tipizzazioni più "universali" che hanno dato vita allo stereotipo del "Classicismo": l"'homme" puro e semplice, con i suoi sinonimi ("nous, on"), o l'uomo qualificato dal punto di vista morale, intellettuale, quando non, semplicemente, mentale ("l'honnête homme, l'habile homme, le fou, le sot").

2 Ritroviamo perciò i "grands hommes" o gli "héros", che, con i "philosophes" non hanno poi molte connotazioni sociali, se non quando la loro grandezza si riferisce anche alla posizione o al rango, i "seigneurs", che "grands" sono di diritto, e i "vaillants" che, ancora una volta, non coincidono perfettamente con loro; e poi, finalmente, i re, i principi, i politici e i favoriti, seguiti subito dopo dai borghesi e dalle "gens du commun". 